\title{
Makro ve Mikro Ölçekteki Lokal Jeoid Tespiti için Enterpolasyon Yöntemlerinin Karşılaştırılması
}

\author{
Mustafa YILMAZ ${ }^{*}$, Birol KURU ${ }^{2}$ \\ ${ }^{1}$ Afyon Kocatepe Üniversitesi, Mühendislik Fakültesi, Harita Mühendisliği Bölümü, AFYONKARAHİSAR \\ (mustafayilmaz@aku.edu.tr) ORCID ID 0000-0003-4192-3226 \\ 2 1706-188 No'lu Lisanslı Harita Kadastro Mühendislik Bürosu, ÇANAKKALE \\ (bkuru.213@gmail.com) ORCID ID 0000-0002-2203-301X
}

\begin{abstract}
Öz
Bu çalışmada, Harita Mühendisliğinin en önemli uygulamalarından biri olan lokal jeoid tespiti için kullanılan noktalar arasındaki mesafenin enterpole edilen jeoid yüksekliklerine olan etkisinin araştırılması amaçlanmıştır. Çalışma kapsamında, $36.5^{0} \leq \varphi \leq 40.5^{0}$ enlem ve $26.5^{\circ} \leq \lambda \leq 33.0^{\circ}$ boylam aralığındaki bölgede makro ve mikro ölçekte iki test ağı oluşturulmuştur. Makro ağda, 85 referans ve 35 enterpolasyon noktası olmak üzere toplam 120 nokta, mikro ağda, 8 referans ve 3 enterpolasyon noktası olmak üzere toplam 11 nokta kullanılmıştır. Elipsoidal yüksekliklerden ortometrik yüksekliklere dönüşüm için gerekli olan lokal jeoid modellerinin tespitinde Ters Mesafe ile Ağırlıklı (TMA), Kriging (KRG), En Küçük Eğrilik (EKE), Radyal Bazlı Fonksiyon (RBF) ve Geliştirilmiş Shepard (MSH) enterpolasyon yöntemleri kullanılmıştır. Hesaplanan Karesel Ortalama Hata değerleri karşılaştııılarak, çalışma bölgesindeki lokal jeoid tespiti için makro ağda GSH yönteminin ve mikro ağda EKE yönteminin en doğru sonucu verdiği belirlenmiştir.
\end{abstract}

Anahtar Kelimeler: Lokal jeoid, enterpolasyon, makro-mikro ölçek.

\section{The Comparison of the Interpolation Methods for Local Geoid Determination at Macro and Micro Scale}

\begin{abstract}
In this study, it is aimed to investigate the effect of distance between the points used for local geoid determination on interpolated geoid heights, which is one of the most important applications of Geomatics Engineering. Within the scope of the study, two test networks at macro and micro scale has been established in the region of $36.5^{0} \leq \varphi \leq 40.5^{0}$ latitude and $26.5^{\circ} \leq \lambda \leq 33.0^{0}$ longitude range. The test network has been established. In the macro network, a total of 120 points, including 120 reference and 35 interpolation points, in the micro network, a total of 11 points, including 8 reference and 3 interpolation points, were used. In the determination of the local geoid models required for the transformation of ellipsoidal heights to orthometric heights, Inverse Distance Weighted (IDW), Kriging (KRG), Minimum Curvature (MCV), Radial Basis Function (RBF), and Modified Shepard (MSH) interpolation methods were utilized. By comparing the estimated Root Mean Square Error values, it was determined that MSH method in the macro network and MCV method in the micro network gave the most accurate result for the local geoid determination in the study region.
\end{abstract}

Keywords: Local geoid, interpolation, macro-micro scale.

\footnotetext{
* Sorumlu Yazar
} 


\section{GİRIŞ̧}

Jeodezinin tanımı; Helmert (1880)'e göre, yeryüzünün ölçülmesi ve haritaya aktarılması bilimidir. Uydu ve uzay bazlı sistemlerdeki teknolojik gelişmeler, jeodezinin günümüzde de temel olarak hala geçerli olan bu klasik tanımının genişletilmesini zorunlu kılmıştır. Buna göre, jeodezinin temel problemi, Dünya'nın şeklini ve gravite alanını zamanın bir fonksiyonu olarak belirlemektir (Torge 2001). Yeryüzünün geometrik şeklini jeodezik olarak modelleme görevi; Dünya'nın merkezi, ekvator ve başlangıç meridyenine göre tanımlanmış üç boyutlu (3B) referans sistemlerinde konum bilgisinin üretilmesini gerektirir (Pearlman vd., 2006). Geleneksel olarak Dünya üzerindeki bir noktanın 3B konum bilgisi iki kısım olarak ele alınmaktadır: Yatay koordinatlar ve düşey konumlama (Yilmaz vd,. 2017). Bu çalışmanın içeriğini düşey konumlama yani yükseklik bilgisi oluşturmaktadır.

Harita mühendisliği uygulamalarının birçoğunda jeodezik anlamda düşey konumlamaya ihtiyaç duyulmaktadır. Düşey konumlama işleminin vazgeçilmez bileşenleri yükseklik ve ilgili datum yüzeyidir. Dünya'nın, topografik düzensizlikler nedeniyle matematiksel olarak ifade edilemeyen fiziksel yeryüzünde gerçekleştirilen jeodezik düşey konum belirleme işlemlerinin değerlendirilebilmesi için geometrik ve matematiksel olarak ifade edilebilen datum yüzeylerine ihtiyaç duyulur. Harita mühendisliğindeki pratik uygulamalar için iki datum yüzeyi kullanılmaktadır. Geometrik olarak tanımlanan elipsoid ve ortalama okyanus seviyesi ile çakışan jeoid. Tanımlanan bu datum yüzeylerine göre elipsoidi referans alan elipsoidal yükseklik ve jeoidi referans alan ortometrik yükseklik ortaya çıkmaktadır.

Günümüzdeki jeodezik ve ölçme uygulamalarında, başlica konumlama aracı olarak kullanılan, Küresel Uydu Bazlı Konumlama Sistemleri (GNSS; Global Navigation Satellite Systems) bir referans elipsoidine göre tanımlanan elipsoidal yükseklik bilgisi üretmektedir. Bunlar geometrik olarak tanımlanmış jeodezik yüksekliklerdir. Bununla birlikte çoğu mühendislik uygulamasında GNSS ölçümleri sonucu elde edilen elipsoidal yükseklikler yerine fiziksel olarak anlamlı olan jeoide göre tanımlanmış ortometrik yüksekliklere ihtiyaç duyulmaktadır. Klasik olarak ortometrik yüksekliklerin elde edildiği geometrik nivelman işlemi oldukça fazla zaman, işgücü ve ekonomik kaynak gerektiren bir ölçme tekniğidir. $\mathrm{Bu}$ bakımdan birçok harita mühendisliği uygulamasında, GNSS ölçümleri sonucu kolay, hızlı ve yüksek doğruluklu olarak elde edilen elipsoidal yüksekliklerin ortometrik yüksekliklere dönüşümü, jeodezinin temel bir görevi haline gelmiştir. Jeoidin referans elipsoid yüzeyi üzerindeki yüksekliği olarak tanımlanan jeoid yüksekliği; elipsoidal ve ortometrik yükseklikler arasındaki ilişkiyi tanımlamaktadır (Şekil 1). Lokal, bölgesel veya global olarak tanımlanabilen jeoid, elipsoidal ve ortometrik yükseklik sistemleri arasındaki dönüşüm için optimal bir parametre oluşturmaktadır (Vanícek ve Krakiwsky, 1986).

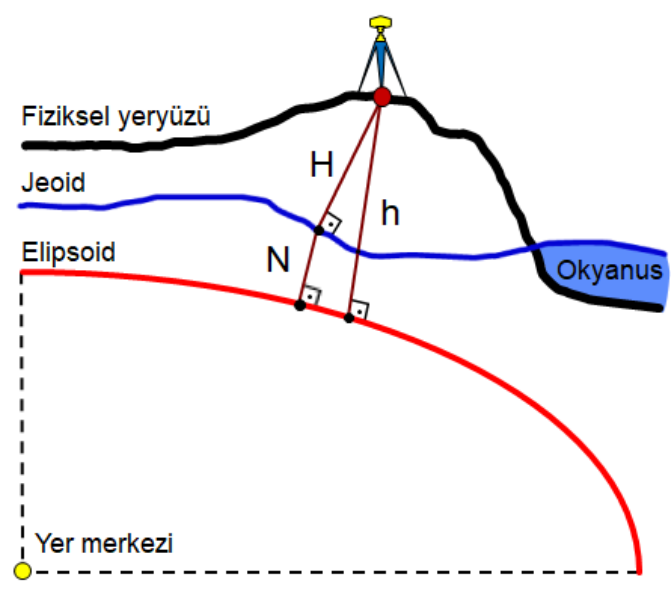

Şekil 1. Elipsoidal ve ortometrik yükseklik ile jeoid arasındaki ilişki

Harita mühendisliğinin pratik uygulamaları için, GNSS ölçümleri ile elde edilen elipsoidal yükseklikler $(h)$ ile geometrik nivelman işlemi sonucu elde edilen ortometrik yükseklikler $(H)$ arasındaki temel bağlantı, $(N)$ jeoid yüksekliği olmak üzere aşağıdaki eşitlik ile tanımlanabilir (Heiskanen ve Moritz, 1967).

$N=h-H$

26.06.2018 tarihinde Resmi Gazete'de yayımlanarak yürürlüğe giren "Büyük Ölçekli Harita ve Harita Bilgileri Üretim Yönetmeliği”, bir önceki yönetmelikte olduğu gibi büyük ölçekli haritacılık çalışmalarında ve mühendislik uygulamalarında gerekli olan ortometrik yükseklik bilgisinin üretimi için mevcut ulusal jeoid modelinin kullanımını veya GNSS/Nivelman noktaları kullanılarak 
gerçekleştirilen enterpolasyon işlemi ile lokal jeoid modelinin oluşturulmasını ve kullanılmasını öngörmektedir.

$\mathrm{Bu}$ çalışma kapsamında GNSS/Nivelman noktaları yardımıyla jeoid yüksekliklerinin enterpolasyonu ile lokal jeoid tespiti kullanılmaktadır. Lokal jeoid modelinin dayanak noktaları yardımıyla belirlenmesinde Ters Mesafe ile Ağırlıklı (TMA), Kriging (KRG), En Küçük Eğrilik (EKE), Radyal Bazlı Fonksiyon (RBF) ve Geliştirilmiş Shepard (GSH) enterpolasyon yöntemleri kullanılmıştır. Dayanak noktalarının birbirine olan mesafesinin enterpole edilen jeoid yüksekliklerine etkisinin araştırılması amacıyla seçilen çalışma bölgesinde makro ve mikro ölçekte iki ayrı test ağı oluşturulmuştur. Oluşturulan lokal jeoid modellerinden enterpolasyon noktalarının jeoid yükseklikleri hesaplanarak bilinen jeoid yükseklikleri ile karşılaştırılmış ve elde edilen jeoid yükseklik farklarına ait Karesel Ortalama Hata $(\mathrm{KOH})$ değerlerine göre en doğru sonucu veren enterpolasyon yönteminin belirlenmesi hedeflenmiştir.

\section{YÖNTEM}

Çalışma bölgesinde oluşturulan makro ve mikro ölçekteki test ağlarında dayanak noktalarına göre jeoid yüksekliklerinin hesaplanmasında kullanılan TMA, KRG, EKE, RBF ve GSH enterpolasyon yöntemleri; Yilmaz (2009), Gullu vd. (2011) ve Yilmaz ve Uysal (2016) tarafindan enterpolasyon yöntemlerinin karşılaştırılması ile elde edilen sonuçlara göre seçilmiştir.

\subsection{Ters Mesafe ile Ağırlıklı}

TMA, enterpole edilecek noktaların yakınındaki dayanak noktalarının uzaktaki noktalara göre ağırlığının daha fazla olması ilkesine dayanmaktadır. Aynı bölgede sürekli değişim gösteren bir veri söz konusu olduğunda, programlama tekniği bakımından uygun ve çok basit bir algoritmaya sahip olmasından dolayı yaygın olarak tercih edilmektedir. TMA yönteminde, enterpolasyon noktasındaki yüzey değeri, dayanak noktalarındaki yüzey değerlerinin ağırlıklandırılmış ortalaması şeklinde hesaplanır. Ağırlıklandırma, dayanak noktasıyla enterpolasyon noktası arasındaki mesafeye bağlı bir fonksiyonla ifade edilir. $\mathrm{Bu}$ yüzden tüm ölçülere aynı ağırlık verilmez, enterpolasyon noktasina yakın olan noktalara daha büyük ağırlık verilir (Yilmaz, 2009).

\subsection{Kriging}

KRG, yer bilimlerinde kullanılabilirliğini kanıtlamış, jeoistatistiksel ve esnek bir enterpolasyon yöntemidir. KRG, matematiksel jeodezide kollokasyon olarak bilinen en iyi lineer yansız hesaplayıc1 (best linear unbiased estimator) ya da en iyi lineer yansız kestirimci (best linear unbiased predictor) olarak tanımlanır (Boogart ve Schaeben, 2002). KRG, bilinen yakın noktalardan alınan verileri kullanarak diğer noktalardaki verilerin optimum değerlerini kestiren bir enterpolasyon yöntemidir. KRG yöntemi, bir bölgede enterpole edilecek olan değerlerin bölgesel bir değişken olduğunu kabul eder ve birbirine yakın örneklerdeki verilerin daha korelasyonlu olması için bölgesel değişken, sürekli bir konumsal çeşitlilik gösterir. KRG yönteminde en uygun ağırlıkları bulmak için, ölçme noktaları arasındaki konumsal bağımlılığın bilinmesi gerekir. $\mathrm{Bu}$ konumsal bağımlılık, kovaryans veya variogram fonksiyonu kullanılarak tanımlanabilir. KRG, daha yakın noktalardan daha fazla etkilenmeyi sağlayan bir ağırlık modeli kullanır (İnal ve Yiğit, 2003).

\subsection{En Küçük Eğrilik}

EKE yöntemi ile elde edilen yüzey modeli, dayanak noktalarından geçen minimum bir bükülmeye uğrayan ince bir plakaya benzer haldedir. Dolayısıyla EKE ile elde edilen yüzey mümkün mertebede ölçü noktalarına yakın bir yüzey olarak tanımlanır. EKE yöntemiyle elde edilen yüzeyde oluşan bükülme veya eğilmeleri kontrol edebilmek için, yüzeyin kenarlarında sınır gerilme katsayısı ile iç kesimlerinde iç gerilme katsayıs1 kullanılır. Sifir ile bir arasında değişen değer, gerilme katsayılarını ifade eder ve sürekli değişim gösterirler. $\mathrm{Bu}$ değer arttıkça yüzeyde oluşan bükülme veya eğilmelerde azalma görülmektedir. EKE yöntemi grid köşe noktalarındaki eğrilik değerlerinin kareleri toplamı en küçük olacak şekilde grid köşe noktalarının yüksekliklerini enterpole etmek için geliştirilmiştir (Yanalak, 2003). 


\subsection{Radyal Bazlı Fonksiyon}

$\mathrm{RBF}$, çok boyutlu verilerin enterpolasyonu için kullanılan bir yöntemdir. Genel olarak sinırlı sayida veri ya da tahmin edilmesi zor olan noktaların tahmininde kullanılmaktadır. RBF, verilere düz ve uyumlu bir yüzey üretme yeteneği açısından arazi modelleme ve yer bilimlerinde tercih edilen bir yöntemdir. Verileri temsil etmede RBF kesin bir yöntemdir. RBF yöntemi ile daha düzgün bir yüzey elde etmek için, bir düzleştirme faktörü olan radyal fonksiyonlar kullanılmaktadır (Yilmaz, 2009).

\subsection{Geliştirilmiş Shepard}

GSH yönteminde, TMA ile benzerlik gösteren fakat bölgesel anlamda mesafenin tersine göre en küçük kareler prensibi ile oluşturulan bir ağırlıklandırma söz konusudur. GSH, dayanak noktalarındaki değerlerin ağırlıklı ortalamasına dayalı olarak yüzey üreten bir enterpolasyon yöntemi şeklinde ortaya çıkmıştır. Basit algoritması ile tercih edilen GSH, yumuşatıcı bir ara değerleyici olarak görev yapabilir (Yilmaz, 2009).

\section{3. ÇALIŞMA ALANI, VERİ, YÖNTEM}

Çalışma kapsamında lokal jeoid tespiti alanı olarak; $36.5^{\circ} \leq \varphi \leq 40.5^{0}$ enlem ve $26.5^{0} \leq \lambda \leq$ $33.0^{0}$ boylam aralığındaki bölge uygulama alanı olarak seçilmiştir. Lokal jeoid tespitinde kullanılan dayanak noktaları arasındaki mesafenin enterpole edilen jeoid yüksekliklerine olan etkisinin irdelenebilmesi amacıyla makro ve mikro ölçekte iki ayrı test ağı oluşturulmuştur.

Makro ağda, enlem, boylam, ortometrik ve elipsoidal yüksekliği bilinen toplam 120 Türkiye Ulusal Temel GPS Ağı (TUTGA) noktasi bulunmaktadır. 120 TUTGA noktasının 85 adedi referans noktası olarak lokal jeoid yüzeyinin oluşturulmasında, kalan 35 adedi test noktas1 olarak enterpolasyon sonuçlarının karşılaştırılmasında kullanılmıştır (Şekil 2). Mikro ağda, enlem, boylam, ortometrik ve elipsoidal yüksekliği bilinen toplam 11 TUTGA ve $\mathrm{C} 1, \mathrm{C} 2$ dereceli sıklaştırma noktası bulunmaktadır. 11 noktanın 8 adedi referans noktası, 3 adedi ise test noktası olarak kullanılmıştır (Şekil 3).

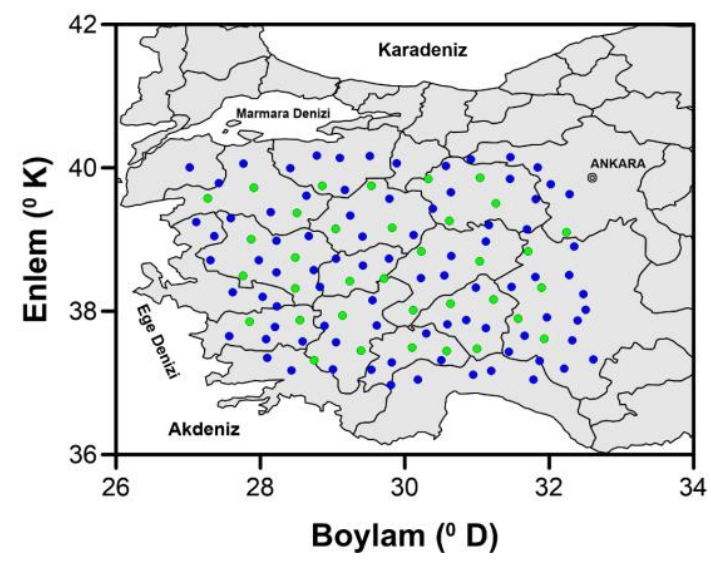

Şekil 2. Makro ağda referans (mavi renkli) ve enterpolasyon (yeşil renkli) nokta dağılımı

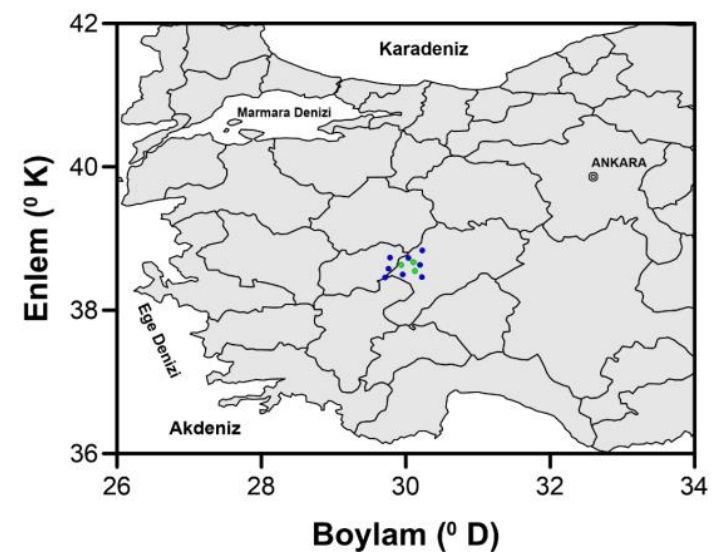

Şekil 3. Mikro ağda referans (mavi renkli) ve enterpolasyon (yeşil renkli) nokta dağılımı

Lokal jeoid tespitinde kullanılan enterpolasyon yöntemlerinin değerlendirilmesi işlemi; makro ve mikro ağlardaki test noktalarının GNSS/Nivelman yöntemi ile bilinen jeoid yükseklikleri ile test noktalarının referans noktalarına göre enterpole edilerek hesaplanmış jeoid yükseklikleri arasındaki farkları $(\Delta N)$ temel almaktadır (Eşitlik 2). Enterpolasyon yöntemleri için genel kabul görmüş bir doğruluk kıstası olması (Yilmaz ve Gullu, 2014) nedeniyle jeoid yükseklik farklarına ait olarak hesaplanan KOH (Eşitlik 3) değeri, değerlendirme ölçütü olarak kullanılmış ve elde edilen $\mathrm{KOH}$ değerleri karşılaştırılarak en doğru sonucu veren enterpolasyon yönteminin belirlenmesi hedeflenmiştir.

$$
\begin{aligned}
& \Delta N=N_{\text {GNSS/Nivelman }}-N_{\text {enterpolasyon }} \\
& K O H=\sqrt{\frac{1}{n} \sum_{k=1}^{n}(\Delta N)^{2}}
\end{aligned}
$$




\section{SAYISAL UYGULAMA}

Enlem, boylam ve jeoid yüksekliği bilinen, makro ağdaki 85 adet ve mikro ağdaki 8 adet referans noktasina göre, Surfer $^{\circledR} 13$ programında öngörülen ayarlar ve katsayılar esas alınarak TMA, KRG, EKE, (multikuadratik) RBF ve GSH kullanılarak her bir enterpolasyon yöntemi için makro ve mikro ölçekte jeoid yüzey haritaları (Şekil 4-13) üretilmiștir.
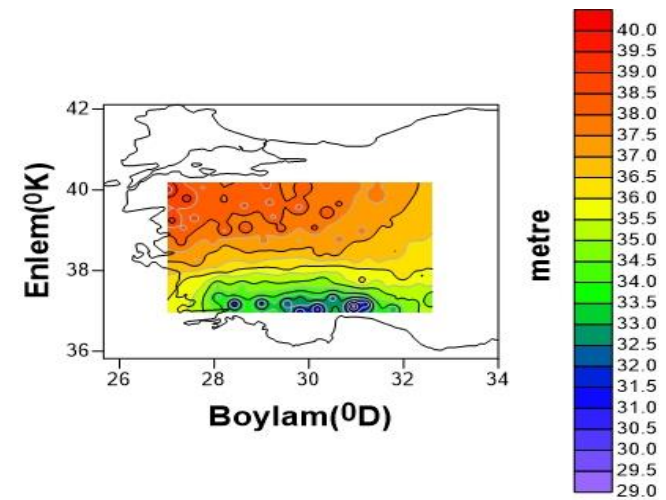

Şekil 4. Makro ağ-TMA jeoid yüzey haritası
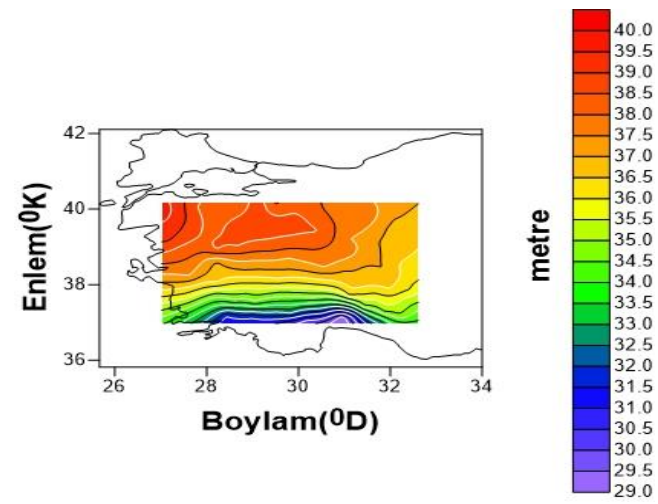

Şekil 5. Makro ağ-KRG jeoid yüzey haritası
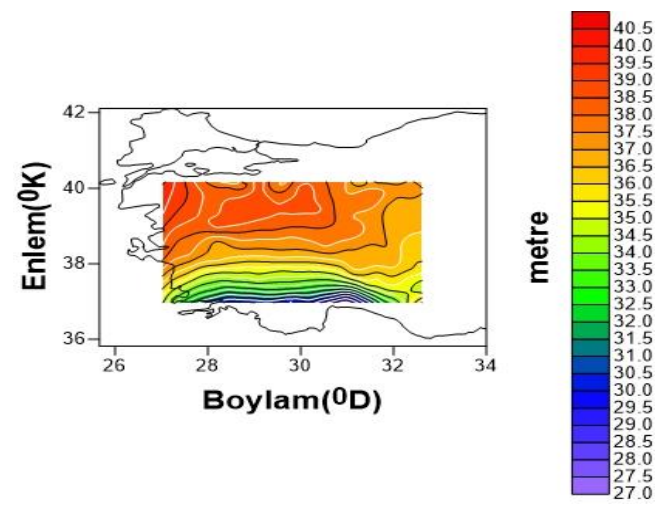

Şekil 6. Makro ağ-EKE jeoid yüzey haritası
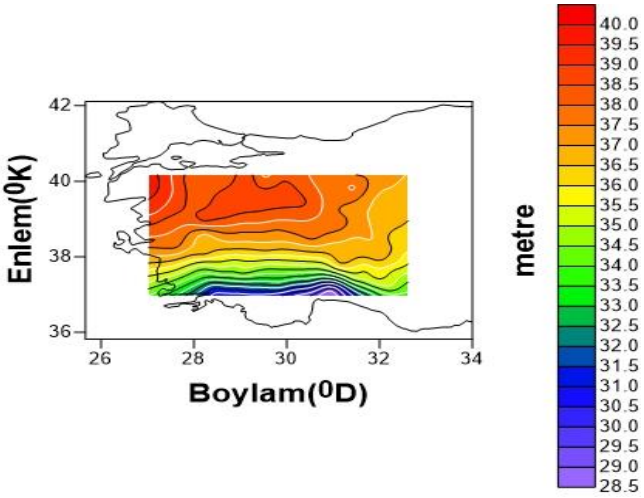

Şekil 7. Makro ağ-RBF jeoid yüzey haritası
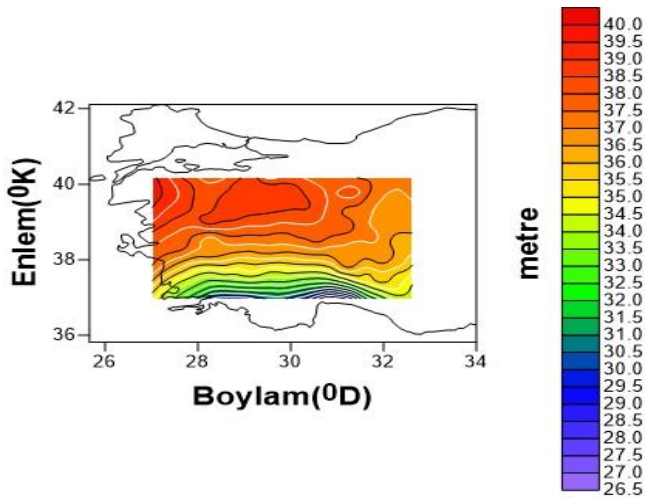

Şekil 8. Makro ağ-GSH jeoid yüzey haritası

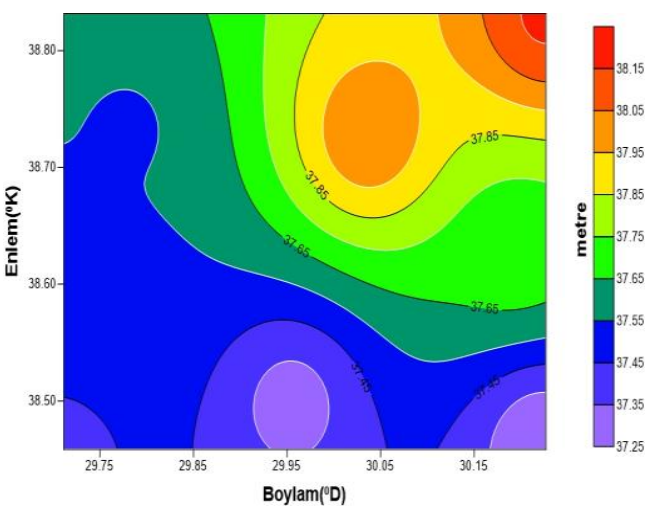

Şekil 9. Mikro ağ-TMA jeoid yüzey haritası

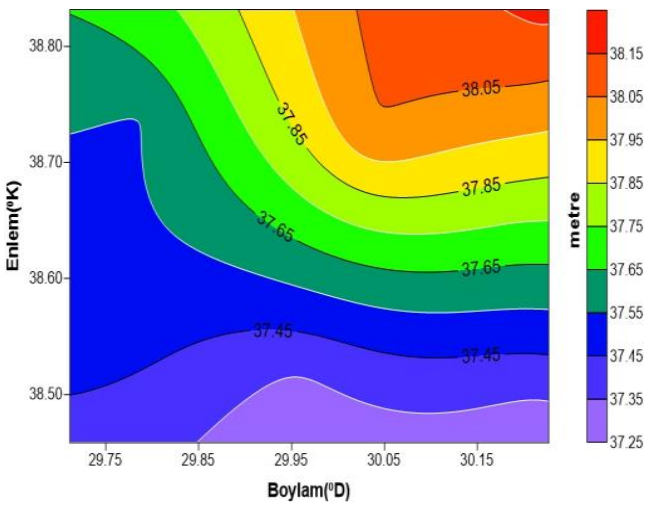

Şekil 10. Mikro ăg-KRG jeoid yüzey haritası 


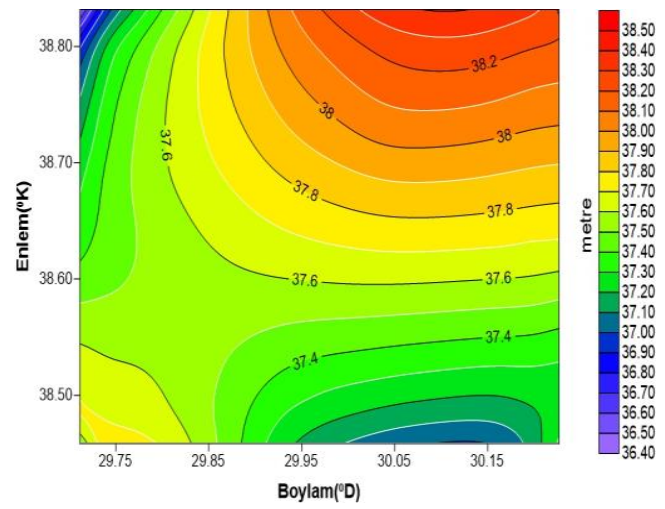

Şekil 11. Mikro ağ-EKE jeoid yüzey haritası

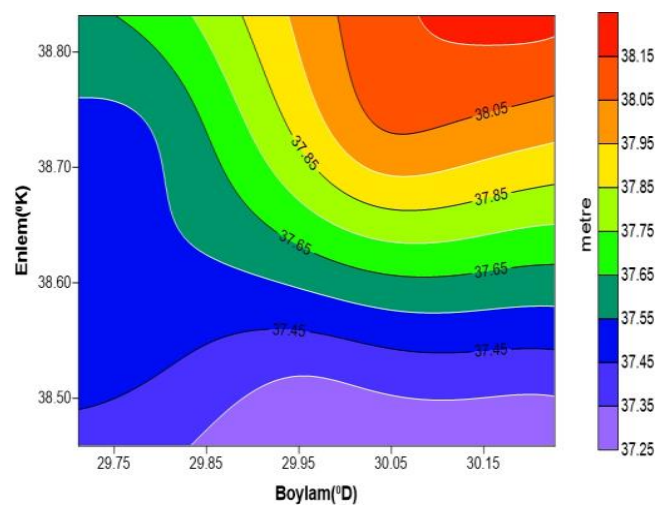

Şekil 12. Mikro ağ-RBF jeoid yüzey haritas1

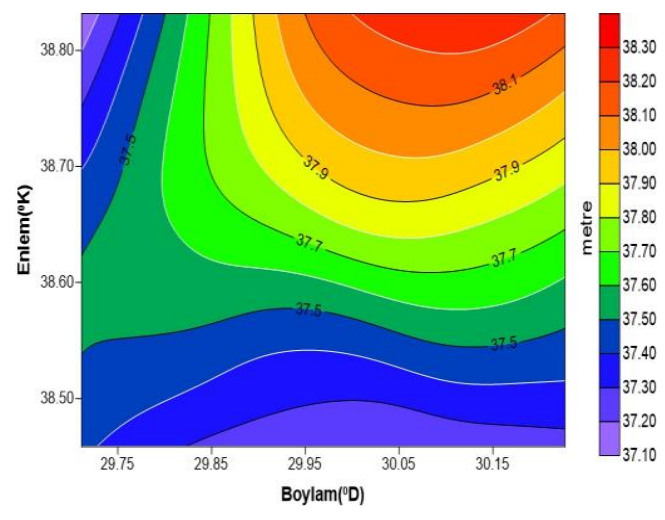

Şekil 13. Mikro ağ-GSH jeoid yüzey haritası

Makro ve mikro ölçekteki jeoid yüzey haritaları kullanılarak test noktalarının jeoid yükseklikleri hesaplanmış ve bilinen jeoid yükseklikleri kullanılarak test noktalarına ait jeoid yükseklik farkları elde edilmiştir. Makro ve mikro ağlarda test noktaları için hesaplanan jeoid yükseklik farklarının istatistiksel bilgileri Tablo 1 ve 2 de verilmektedir.
Tablo 1. Makro ağda elde edilen fark değerlerinin istatistikleri (birimler m.)

\begin{tabular}{llcccc}
\hline & Min. & Maks. & Ort. & Ranj & KOH \\
\hline TMA & -1.481 & 0.915 & 0.230 & 2.396 & 0.551 \\
KRG & -0.586 & 0.567 & 0.007 & 1.153 & 0.223 \\
EKE & -0.517 & 0.465 & -0.022 & 0.982 & 0.222 \\
RBF & -0.585 & 0.497 & -0.010 & 1.082 & 0.224 \\
GSH & -0.558 & 0.334 & -0.050 & 0.891 & 0.203 \\
\hline
\end{tabular}

Tablo 2. Mikro ağda elde edilen fark değerlerinin istatistikleri (birimler m.)

\begin{tabular}{llrrrc}
\hline & Min. & Maks. & \multicolumn{1}{c}{ Ort. } & Ranj & KOH \\
\hline TMA & -0.224 & 0.113 & -0.024 & 0.337 & 0.177 \\
KRG & -0.137 & 0.080 & -0.010 & 0.217 & 0.113 \\
EKE & -0.047 & 0.071 & 0.001 & 0.118 & 0.062 \\
RBF & -0.120 & 0.059 & -0.013 & 0.178 & 0.094 \\
GSH & -0.159 & 0.042 & -0.046 & 0.201 & 0.103 \\
\hline
\end{tabular}

\section{SONUÇ VE ÖNERILLER}

$\mathrm{Bu}$ çalışmanın amac1; enterpolasyon problemi olarak ele alınan makro ve mikro ölçekte lokal jeoid tespiti için kullanılan yöntemlerin karşılaştırılmasıdır. Çalışma kapsamında elde edilen verilerin tamamı (Şekil 3-14 ve Tablo 12) birlikte değerlendirildiğinde, makro ve mikro ağlardaki test noktalarının jeoid yüksekliklerinin, söz konusu ağlardaki jeoid yüksekliği bilinen referans noktalarına dayalı olarak kestirilmesi probleminde, en küçük $\mathrm{KOH}$ değerini veren yöntemin kullanılabilir en iyi yöntem olduğu düşüncesinden hareketle; aşağıdaki sonuçlar çıkarılmış ve önerilerde bulunulmuştur:

- Çalışma kapsamındaki enterpolasyon yöntemlerinin tamamının, genel olarak lokal jeoid tespitinde kullanılabilir olduğu görülmektedir.

- Makro ağ için en küçük $\mathrm{KOH}$ değerini $( \pm 0.203 \mathrm{~m}) \mathrm{GSH}$ yönteminin verdiği, KRG, EKE ve RBF yöntemlerinin birbirine çok yakın sonuç verdiği, TMA yönteminin ise en düşük doğruluğa sahip olduğu görülmektedir.

- Makro ağ için en küçük ranj (minimum-maksimum) değerini $(0.891 \mathrm{~m})$ veren GSH yöntemi en yüksek modelleme doğruluğuna sahiptir.

- Mikro ağ için en küçük $\mathrm{KOH}$ değerini $( \pm 0.062 \mathrm{~m})$ EKE yönteminin verdiği, diğer yöntemler arasinda ise $\mathrm{RBF}<\mathrm{GSH}<\mathrm{KRG}<$ 
TMA şeklinde bir sıralama olduğu görülmektedir.

- Mikro ağ için en küçük ranj değerini $(0.118 \mathrm{~m})$ veren EKE yöntemi en yüksek modelleme doğruluğuna sahiptir.

- Hem makro hem mikro ağda TMA yönteminin en düşük doğruluğu vermesi nedeniyle, ağırlıklandırma işleminin sadece referans noktası ile test noktasi arasındaki mesafeye göre gerçekleştirilmemesi, referans noktalarının seçiminde birbirine olan uzaklığının yani uygun coğrafi dağılımın da göz önünde bulundurulması gerektiği ortaya çıkmaktadır.

Makro ve mikro ağlardaki en küçük $\mathrm{KOH}$ değerlerine karşılık gelen jeoid yükseklik farkları Şekil 14 ve 15 de haritalandırılmıştır.

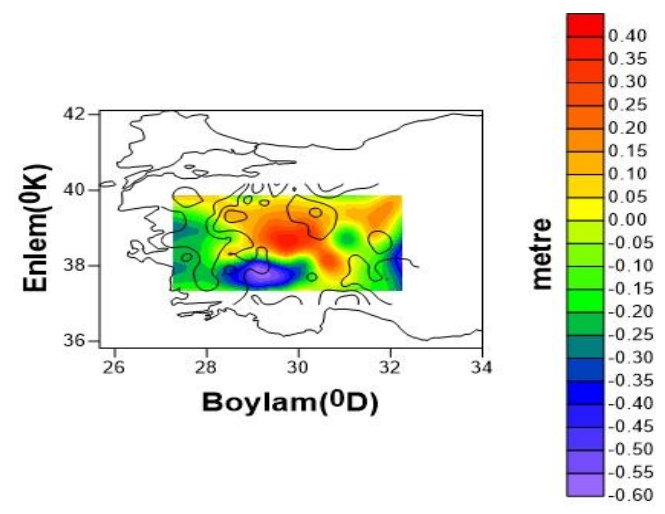

Şekil 14. Makro ağ-GSH jeoid fark haritası

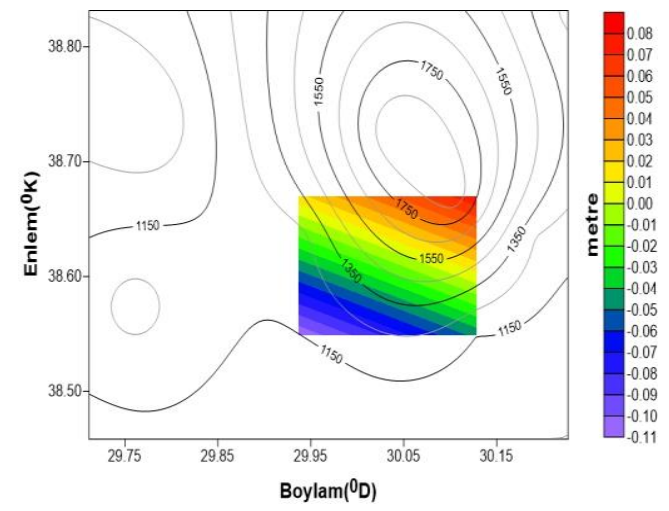

Şekil 15. Mikro ağ-EKE jeoid fark haritası

$\mathrm{Bu}$ çalışma kapsamında elde edilen tüm sonuçlar irdelenecek olursa; dağlık olmayan bir topografyada lokal jeoid belirleme çalışmaları için; referans noktaları arasındaki mesafenin 15 km'den büyük olduğu alanlarda, mesafeye bağlı ağırlıklandırma işlemindeki yumuşatma etkisi nedeniyle GSH yönteminin, referans noktaları arasındaki mesafenin 5 km'den küçük olduğu alanlarda, fiziksel yeryüzünün düz bir yüzey varsayılması nedeniyle EKE yönteminin, kullanılabileceği öngörülmektedir.

\section{KAYNAKÇA}

Boogaart, K.G., Schaeben, H. (2002). Kriging of regionalized directions, axes and orientations I. Directions and axes. Mathematical Geology, 34(5), 479-503.

Gullu, M., Yilmaz, I., Yilmaz, M., Turgut, B. (2011) An alternative method for estimating densification point velocity based on back propagation artificial neural networks. Studia Geophysica et Geodaetica, 55(1), 73-86.

Heiskanen, W.A., Moritz, H. (1967). Physical Geodesy. W.H. Freeman, San Francisco.

Helmert, F.R. (1880). Die Mathematischen und Physikalischen Theorieen der Höheren Geodäsie (Mathematical and Physical Theories of Higher Geodesy). Druck und Verlag von B. G. Teubner, Leipzig.

İnal, C., Yiğit, C.Ö. (2003). Jeodezik uygulamalarda kriging enterpolasyon yönteminin kullanılabilirliği. TUJK 2003 Yllı Bilimsel Toplantısl. Coğrafi Bilgi Sistemleri ve Jeodezik Ağlar Çalıştayl, 24-26 Eylül 2003, Konya, 177-185.

Pearlman, M., Altamimi, Z., Beck, N., Forsberg, R., Gurtner, W., Kenyon, S., Behrend, D., Lemoine, F.G., Ma, C., Noll, C.E., Pavlis, E.C., Malkin, Z., Moore, A.W., Webb, F.H., Neilan, R.E., Ries, J.C., Rothacher, M., Willis, P. (2006). Global Geodetic Observing System-considerations for the geodetic network infrastructure. Geomatica, 60(2), 193-204.

Torge, W. (2001). Geodesy, $3^{\text {rd }}$ edition. Walter de Gruyter, Berlin-New York.

Vanícek, P., Krakiwsky, E.J. (1986). Geodesy: The Concepts, $2^{\text {nd }}$ edition. North-Holland, Amsterdam.

Yanalak, M. (2003). Effect of Gridding Method on Digital Terrain Model Profile Data Based on Scattered Data. Journal of Computing in Civil Engineering, 17(1), 58-67.

Yilmaz, I., (2009). A research on the accuracy of landform volumes determined using different interpolation methods. Scientific Research and Essay, 4(11), 1248-1259.

Yilmaz, M., Gullu, M., (2014). A comparative study for the estimation of geodetic point velocity by artificial neural networks. Journal of Earth System Sciences, 123(4), 791-808. 
Yilmaz, M., Uysal, M. (2016). Comparison of data reduction algorithms for LiDAR-derived digital terrain model generalisation. Area, 48(4), 521-532.

Yilmaz, M., Turgut, B., Gullu, M., Yilmaz, I. (2017). Application of artificial neural networks to height transformation. Technical Gazette, 24(2), 443-448. 